\title{
How to Leverage Virtual Learning Communities for Teaching Agile Communication Skills? The eGroups Case at the University of Münster in Germany and Massey University in New Zealand
}

\section{Christina vom Brocke*}

University of Teachers Education PHGR, Switzerland

E-mail: Christina.vomBrocke@phgr.ch

*Corresponding author

\begin{abstract}
Global business life nowadays is marked by quickly evolving forms of cooperation. These are often set in virtual space where various members from different countries are brought together in order to collaborate. This trend calls for specific abilities in communication that respond to the challenges evoked by the ever evolving and newly forming nature of international virtual project teams. In this paper, these abilities are called "agile communication skills". The paper reports on the conceptualisation and implementation of a Virtual Learning Community (VLC) in a longitude study designed to foster socalled "agile communication skills". Our research presents an approach where VLCs are used in order to create authentic evolving cooperations between students. For this matter internet technology seemed to prove as a key enabler. However, the mere use of technology does not suffice on its own. We, thus, identified design principles of VLCs that appear to be critical factors for successfully implementing such communities. We applied design-oriented research by grounding our model in prior work and formatively evaluating it in multiple case studies over a period of two years. In this paper we present the matured model and show what features characterise an eLearning environment to teach agile communication skills in a university setting. In addition we report on evaluating this model in a real-life application scenarios by giving illustrating examples from the final case study between the players involved: the Massey University in New Zealand and the University of Münster in Germany.
\end{abstract}

Keywords: Virtual Learning Communities; Evolving Cooperations; Agile Communication; eGroups; Languages for Specific Purposes; Intercultural Communication; Higher Education

Biographical notes: Christina vom Brocke is senior lecturer at the University of Teachers Education PHGR in Switzerland. She holds a PhD in Applied Linguistics from the University of Münster in Germany. She teaches first and second language acquisition and her research focus lies in teaching languages for specific purposes, foreign language education in VLCs, intercultural communication, and innovative teaching scenarios in higher education. She is an invited speaker at a number of universities, such as the University of Liechtenstein, Münster University in Germany, and Massey University in New Zealand. 


\section{Introduction}

In today's global business the ability to communicate successfully and across cultures plays a more and more crucial role. Acting economically requires the ability for all business partners to both acknowledge and amend one's own intercultural mindset and to be open-minded towards the one of the business partner. These requirements are actually as old as time since international trade has always existed. What is still vibrant though is the speed and the manifold options offered through virtuality which has made its way into global business processes (Hossain \& Wigand, 2004). The options of virtual communication that allow for a unique and novel way of collaboration come along with new challenges regarding communicative skills (Wainfan \& Davis, 2004).

The new challenges arise due to the velocity in which intercultural teams are now collaborating online, forming, changing, etc. One reason for this is that virtualisation allows for interlinking people (Herrell, Whiteley, \& Crumb, 2010). For a set time people who have never met before and might never meet again are placed into a work relation. What results are new challenges posed upon successful communication: The businessrelated collaboration takes place in a reduced communicative space such as via email, chat, video-conferences or even social media tools such as Facebook, Skype or Google Plus. New teams form up for a specific time frame and collaborate from various places of origin, they coordinate work processes online, jointly work on documents stored in "the cloud", etc. (European Commission Enterprise and Industry, 2009). Thanks to freedom of space and time, new forms of work-life routines have evolved, allowing people to work from at home ("home offices") and from there possibly also in a number of teams at the same time. The new form of global collaboration is extremely dynamic and can only be planned and anticipated on a very rudimentary basis. It evolves with time and shall therefore be called "evolving cooperation" (vom Brocke, 2010).

Evolving cooperations come along with a whole new set of potentials but also challenges. Often, members are involved in various virtual collaborations in parallel which normally run on a very quick scale with a typically short project time frame. Collaboration is often reduced to the mere language exchange and collaboration partners will not necessarily meet physically but only virtually. Within few weeks, new tasks have to be aligned, creative and innovative solutions need to be developed together and documented. The time to meet is reduced to virtual exchange on the job so there is little space to get to know and estimate one another socially. Negotiation of meaning and mutual understanding evolves through agreeing and disagreeing so that misunderstandings are prone to arise (Walker \& vom Brocke, 2009). Such evolving collaborations require the ability to adapt communicative action to the evolving communicative requirements. These abilities have been coined "agile communication skills" (vom Brocke, 2010).

The article is structured as follows: The upcoming section introduces the two concepts of "evolving cooperation" and "agile cooperation" as a theoretical background. We then present our specific research approach, followed by our research results. Applying design science research we report on both (a) the design of a model for leveraging VLCs for teaching agile communication skills - the eGroups-Model - and (b) results of its evaluation in a case at the University of Muenster in Germany and Massey University in New Zealand. We conclude with a brief summary and outlook on future research opportunities. 


\section{Theoretical Background}

\subsection{Characterising Evolving Cooperation}

Today's business world is characterised by virtual project teamwork. Vitality in global business communication comes along with great potentials such as time- and cost reductions and also $\mathrm{CO}_{2}$ reductions as travelling becomes more and more superfluous (Herrell, Whiteley, \& Crumb, 2010). As a consequence, cooperations may evolve quickly and more and more on a short scale which coins a new form of cooperation.

Analysing prior research in the field, we can observe that the quality of this cooperation comes up with new characteristics relevant for teaching communication skills (Wainfan \& Davis, 2004). While prior research elicited how to prepare for special kinds of communication contexts (Hutchinson \& Waters, 2006), we now can hardly assume a given communication context we could prepare for. A vast amount of research has been crafted in the field of intercultural communication, for instance (Gudykunst, 2003). Most of these studies, however, looked into characteristics of specific cultures or of collaborations between two selected national cultures (Hofstede, 1980; Trompenaars \& Hamden-Turner, 1997). Communication strategies, to do business with China, for example, have been largely studied from a western perspective during past years (Gibson, 2002). Likewise, researchers from the field of Applied Linguistics (House \& Rehbein, 2004), and English for Specific Purposes (Dudley-Evans \& St. John, 1998), in particular, have explored communication strategies for specific communication contexts and objectives. Examples include, how to conduct interviews, give presentations, resolve conflicts, or simply communicate using English as a lingua franca (Seidlhofer, 2001).

These studies do all provide valuable insight. Given the special characteristics of virtual collaboration on a global scale, however, we now also need to consider that communication partners can hardly prepare for specific communication contexts since the factors driving each specific context can change very dynamically. In virtual collaborations, it is unlikely to face a national target culture, for example, since a great diversity of cultures is involved in collaborations regularly and the mix of these cultures is frequently changing from project to project. In these situations, we may perhaps be able to prepare for the project targets but we also need to learn how to communicate particularly lacking information about our collaboration team partners, their goals, their particular skills and their social habits in collaboration. We need to learn how to explore the context and to efficiently adopt to it.

Since such situations go beyond the scope of conventional intercultural collaboration, we use the term "evolving cooperation" in order to foster our research on specific communication challenges. In more detail, evolving cooperations are characterised by a) constitutional characteristics which define a cooperation as an evolving cooperation, and b) typical characteristics, which are very often present in an evolving cooperation. They will be delved into in the following section:

\section{(a) Constitutional Characteristics}

A cooperation shall be called "evolving cooperation" if it fulfils the following constitutional characteristics: Diversity of stakeholders, common goals, new formation as well as project-based work:

- Diversity of stakeholders: Each stakeholder of the community has their own unique communication context. The context is characterised especially by each person's subject-based but also their intercultural background. 
- Common goals: The team members strive after the same common goal and, therefore, also have the task to elaborate on their tasks jointly. As part of the same common goal, it is possible that minor goals might differ from team member to team member.

- New Formation: The project team is newly constituted bringing together team players who have not met or worked together before.

- $\quad$ Project-based cooperation: The project team works on an innovative task which is not carried out on a routine basis and works jointly only within a restricted time frame.

Further characteristics are prone to coincide but not necessarily. They are, therefore, called typical characteristics (vom Brocke, 2010):

\section{(b) Typical Characteristics}

Diversity is a characteristic trait of evolving cooperations. It can be described further by means of typical characteristics:

- Interculturality: Often, members of a (newly constituting) team are of diverse international and intercultural origin. On the one hand, team members working in a company may come from diverse backgrounds. On the other hand, the whole company may act on an international level so that team members may even reside in different countries working together for reaching the project scopes.

- Interdisciplinarity: Stakeholders in the team may have a specialised and unique professional background and their own individual experience. In order to gather the potential of a team, professional diversity may bring unique opportunities to harvest diverse expertises for creating solutions for or simply working on a common project goal.

- Interlinguality: The aspect of interculturality goes hand in hand with the choice of languages to use since it is often enough the case that none of the team members are mother tongue speakers of the same language. While team members, thus, may have to choose a third language in which to converse, in most cases statistically English as the Lingua Franca is chosen (Seidlhofer, 2001) or otherwise, a language serving as the mother tongue for one party and as a second language for another. In collaborations with neighbouring countries, the parties involved may choose to both speak their mother tongues and to rely upon each other's respective passive knowledge of the other language (Beerkens, 2010).

Evolving cooperations can be illustrated by way of an example: When universities for in-stance apply for research funding from the European Union as part of the European Framework - a considerable fund raising possibility for research across Europe, often partners from three different countries need to be aligned for fulfilling the project requirements. Project members are already quite different to one another due to their institutions, which have their specific research focuses and are spread out across Europe. The common goal to strive for lies in creating a project application, which needs to be completed by a specific point in time. Typically team members are from interculturally different origins and often they also have a different interdisciplinary background, plus they speak various languages, which is an asset of interlinguality.

Evolving cooperations show specific characteristics: Every cooperation might be coined individually from one specific point in time to another depending on the context and the parties involved. As to each specific set up and context the characteristics can vary individually and also change during the cooperation. For the participants involved, successful communication in evolving cooperations implies the ability to adapt the personal style of communication to changing circumstances and the individual 
interlocutors. Such flexibility requires the abilities to sense the situational context and to adapt dynamically. These abilities are referred to as so-called "agilities". On the basis of existing models for languages for specific purposes, specific agilities have been identified for evolving cooperations and are presented in the following chapter.

\subsection{Defining Agile Communication Skills}

In evolving cooperations, the situation of the communication is typically characterised by a certain unpredictability: the specific constellation is typically newly set up, the stakeholders collaborate for the first time and may be changing during the collaboration, and each stake-holder may be involved in various projects with different team members in parallel. Because of the largely unpredictable communicative contexts in evolving cooperations, it is not enough to build up competences for specific professional or cultural contexts. Much more than that it seems vital to build up a core competency in communicatively handling a largely context-reduced space, that is to be able to construct context by means of agile communication. In other words, rather than preparing individual situations, it seems important to enable to flexibly handle unpredictable situation with diverse collaboration partners. Referring to former studies in the field of management and engineering, this ability shall be explored further under the term "Agility". Likewise to the phenomenon studied in our research, concepts like agile project management (Boehm \& Turner, 2004), agile software development (Cockburn, 2001), and agile software engineering (Hazzan \& Dubinsky, 2009) have been coined, just to name a few. Following on these contributions, we, thus, consider the term "agile communication skills" appropriate to characterise the new challenges to be faced when entering evolving cooperations.

In our studies, more specifically the term agility refers to the ability of dynamically adapting to both new acting situations and unknown and potentially also changing collaboration partners. Because of individually differing characteristics it is important for collaboration partners to continuously monitor and adapt their communicative behaviour on various levels to the momentary requirements of the previously unforeseen communicative situation. Drawing on models about languages for specific purposes (vom Brocke, 2010, pp. 10-34), agilities can be deducted with respect to (1) professional aspects, (2) context-oriented aspects, (3) personal or social aspects, and (4) intentional aspects. These aspects are framed by the agility to (5) adapt on a linguistic level.

- Interdisciplinary Agility: Evolving cooperations are characterised by diverse stake-holders who each have a unique professional (and cultural) background and are typically from diverse disciplines. These characteristics incorporate a challenge to communication due to differing knowledge elements, cognitive structures as well as adequate mediating structures among interlocutors. Interdisciplinary agility refers to the ability to clearly and flawlessly communicate on a subject level despite differing individual professional backgrounds among interlocutors (which Buhlmann \& Fearns (2000, p. 369) refer to as "asymmetrical knowledge structures"). Communication is enabled by means of communication and serves the interdisciplinary information exchange. The challenge requiring an interdisciplinary agility lies finding out where differing knowledge elements and cognitive structures lie and how these can be mediated so that every member involved understands. This also comprises the ability to explore and mediate expectations or the lack of knowledge about the characteristics, the interlocutor may bring in (Davies, 2003). 
- Intercontextual Agility: In evolving cooperations, each team member brings in their own specific context. This comprises the working culture, the private situation that impacts on the working context, the gender or the position at work. These elements create an effect on joint communication as communication strategies may be linked to contextual elements. Knowing about and including the contexts of team members may have positive effects on joint collaboration. Intercontextual agility means the ability to consider the various contexts stakeholders may bring in and to transfer them each according to the working goals and requirements. Apart from the various stakeholders and their contexts, this also comprises the specific elements of each academic background, the ratio between communication in a defined language for specific purposes and action, the hierarchical status of team players involved, the individual intercultural backgrounds, the social distance, the gender of the linguistic competence in general. Among these are also both synchronous and asynchronous aspects of collaboration which may occur due to time shifts, but also different psychological and socio-cultural backgrounds of everyone involved that may become apparent (Hutchinson \& Waters, 2006).

- $\quad$ Interpersonal Agility: In evolving cooperations members are put together in a team who have not met before. Not knowing one's partner on a social and personal basis increases the challenge to communicate with one another as it remains unclear in how far messages from the partner can be interpreted, in how far directness or indirectness in communication are expected, which behaviour may lead to face threats or if partners are more atmosphere-related or rather truth-oriented (Blum-Kulka, House, \& Kasper, 1989). This is especially increased if partners are from a different culture or speak another mother tongue. Interpersonal agility comprises the ability to explore adapt to the intercultural backgrounds of each team player involved, the personal characters, their points of views, ways of life, and emotions (Baumann \& Shelley, 2006). Specifically, this refers to the ability to sense and adapt to the individual expectations, the behaviours, the reactions towards the propositional utterances of the interlocutors involved. Moreover, this also comprises a certain ability to anticipate the knowledge, the behaviour as well as the individual background of the hearer. He or she who is interpersonally agile, is successful in both finding out and consider the individual requirements and needs of his or her team partners and at the same time to also communicate his or her personal requirements and needs just as well.

- Interintentional Agility: In evolving cooperations, people are combined who generally thrive for the same global goal. However, each team member may have a specific interpretation of how to reach the goal or how to bring in him- or herself. Interintentional agility is the ability to consider and align personal goals with those of the team players involved. In evolving cooperations, the goals to be reached by the end of the cooperation may only be vaguely sketched out at the beginning of a joined co-operation. Since individual stakeholders may show opportunistic behaviour in that they may not always act according to their professional role but rather in favour of their personal interests, the intentions of each stakeholder involved in a project team may be left partly blurred (Holmes \& Stubbe, 2004). Like other factors in communication, these aspects need to be explored further and considered in the personal communication strategies during the evolving cooperation (Bührig \& Meyer, 2004). Moreover, this agility also comprises the ability to mediate, negotiate and align personal goals and intentions with those of the other parties involved.

The four agilities explained here are surrounded by the linguistic agility which enables the hearer-oriented transmittance of information (Hutchinson \& Waters, 2006; House \& Rehbein, 2004). Linguistic agility is the basis of agilities and communication. 
Linguistic agility comprises a certain degree of linguistic correctness in that communication must be understandable for the other parties involved. Yet, what is much more important than linguistic correctness, is to have the agility to negotiate meaning with communication partners successfully in a way that the intended effect is attained which ultimately impacts on the collaboration (Scollon \& Scollon, 1995). For the foreign language for specific purposes classroom which aims at developing and fostering the agilities needed in evolving situation, the linguistic agility is the core competency at the focus.

\section{Research Design}

This paper reports on research aiming at mediating agile communication skills in teaching scenarios. In more detail, we tackle the following research questions:

- $\quad \boldsymbol{R Q 1 :}$ What features characterise an eLearning environment to teach agile communi-cation skills in a university setting?

- $\quad$ RQ2: In how far does such an eLearning environment prove to be useful in reallife application scenarios?

In order to address these research questions, we basically apply a design science research approach (Hevner et al., 2004). We deem this approach appropriate, since we strive for an innovative solution to a yet unsolved problem. Hence, we first present conceptual ideas derived from literature on features characterising an eLearning environment recommendable to mediate agile communication skills. We summarize our findings by means of a conceptual model, we refer to as the eGroups model. Second, we evaluate this model based on practical applications we conducted from 2006 to 2008. In the following we give an overview of the four rounds of concurrent design and evaluation:

- Case 1: The first eGroups implementation took place in the second semester 2006/2007 as part of the course "Cultural Studies USA" in cooperation with the University of Münster, Germany and the University of Washington, Seattle in the US. Apart from face-to-face on-site lessons, students had the task to discuss on controversial discussion tasks in English with their American counterparts via an online learning platform hosted at the University of Münster.

- Case 2: The second eGroups implementation took place during the first semester in 2007 as part of the course "English for Social Sciences and the Humanities" at the University of Münster in Germany and the course "German for Advanced Learners" at the School of Languages, Department for Social Sciences and the Humanities at the Massey University in New Zealand. Apart from on-site seminars, students had the task to interact with the students from the other country in both English and German. Focus of their interaction was placed on the task to work on socio-critical topics comparing New Zealand and Germany where students could bring in both their academic but also their regional knowledge. The tasks of the students from Germany differed slightly to those of New Zealand since they had to be aligned to their respective course and curriculum requirements. Yet, the overarching creed was mutual support in providing, discussing and exchanging country-specific or language-specific help and information in order to solve the tasks. One challenge lay in integrating two different platforms that had to be used since each university required the use of their own platform.

Case 3: The third eGroups implementation took place in the second semester in $2007 / 2008$ as part of a two-week intensive course. Again students from the course "English for Social Sciences and the Humanities" at the University of Münster in 
Germany collaborated with students from Massey University in New Zealand in both English and German. This time the tasks were narrowed down to the topics "environment" and "culture" about which they had to write a joint term paper. The best paper was selected for publication in a student journal. As a new tool in this cooperation voicetools were integrated in the course work allowing students to speak live to their counterparts on the other side of the planet.

- $\quad$ Case 4: The fourth eGroups implementation took place in the second semester in 2008. This time the course was stretched to a two-month cooperation again with students from the course "English for Social Sciences and the Humanities" from Münster, Germany and their German learning counterparts at Massey University, New Zealand. The task was to explore a topic in the thematic range of "Globalisation and Localisation Opportunities and Challenges" in English and German which would again involve comparing aspects in both Germany and New Zealand and a joint term paper in the end. Students also had the task to carry out and analyse a small empirical study to serve their topic. The same technical equipment was used in this course.

During the four ventures described, the eGroups approach was continuously monitored, evaluated and further designed. In the following, we present the eGoups model in its most recent refinement including the lessons learned from the first three case studies. This model presents our results regarding RQ1. In addition, we can also report on the evaluation of the model in its final stage, which we conducted in the fourth case study. These findings provided results relating to RQ2.

\section{Results}

\subsection{Presenting the eGroups-Model}

\subsubsection{Overview of the Model}

The basic idea in the eGroups approach lies in interlinking learners from different institutions in a VLC in project work for a specific time span (Walker \& vom Brocke, 2009). By this, the approach substantially makes use of the affordances, VLCs can offer (Schwienhorst, 2003; Stickler \& Lewis, 2008; Garrison et al., 2001; vom Brocke et al, 2010). Evolving cooperations actually typically arise in virtual space and setting up a learning approach in virtual space also brings in the opportunity to interlink learners from different institutions if not from different countries (Belz, 2003; Warschauer \& Meskill, 2000). A VLC follows the intention to create an authentic space in which learners can foster their agilities in a purpose-oriented way (Hudson \& Bruckmann, 2002). It is also expected that an authentic space may motivate learners to meet the challenges imposed upon them in evolving cooperations (Rilling \& Dantas-Whitney, 2009). What is more, there is reason to believe that in practical situations learners are prone to sense in how far their own agility and that of their partners actually influences the success of a joined venture in their project work (O'Dowd, 2006). Last but not least, such an approach is also expected to foster the translation of theoretically acquired academic content into practice (Mangenot \& Nissen, 2006).

The following presents an approach for fostering agile communicative competence in evolving cooperations, which can be installed via a VLC in a higher educational setting. Fostering agilities as part of the foreign language classroom 
dedicated to teaching languages for specific purposes actually seems fitting well since students are required to focus on language use on a specialised content level (Davies, 2003). As to a holistic eLearning approach for the tertiary level, research on VLCs delivers an important basis for the development of such an eLearning approach (Garrison et al., 2001; Belz, 2003; Hauck \& Youngs, 2007; O’Dowd, 2006; vom Brocke, 2010). In this concept, mostly either pedagogical, organisational or technical design aspects are covered (vom Brocke et al., 2010). In the eGroups approach, all three aspects are aimed at holistically as design principles (Walker \& vom Brocke, 2009). For every one of the three design principles, specific parameters are presented. The following visualisation presents the most important design principles and parameters for this study:

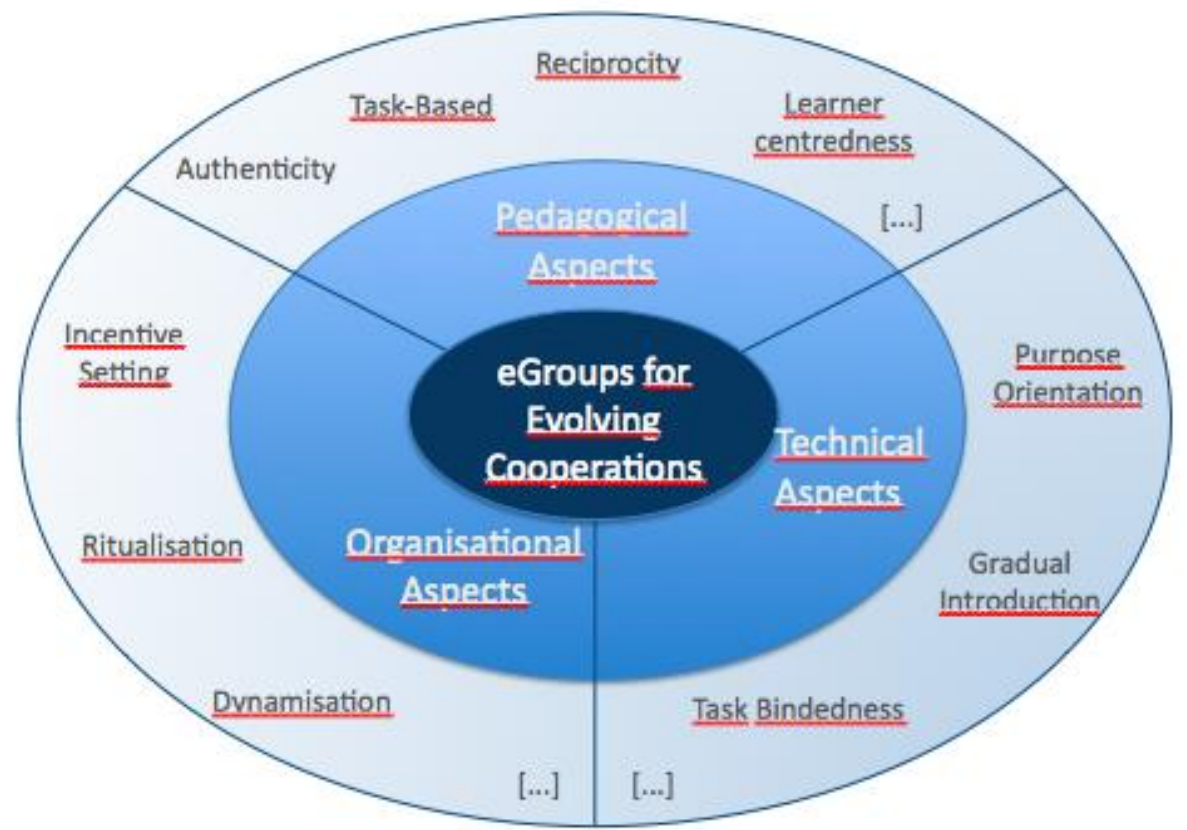

Figure 1. eGroups-Approach for Fostering Agilities in Evolving Cooperations

The eGroups approach aims at creating evolving cooperations via a VLC in tertiary education in order to foster agile ability to act of students. While the learning approach is clearly driven and enabled by IT, we account for learning environments as socio-technical systems (cf. Salembier \& Hakim, 2002). Hence, also non-technical areas of design have been taken into account in order to actually meet learning objectives (cf. Garrison et al., 2001). Focusing on learning in the tertiary sector, the following three areas of design have been identified: (a) pedagogical design principles, (b) organisational design principles, and (c) technical design. For each area, design principle have been studied and formatively evaluated during a two years series of case studies. These design principles will be presented and discussed in the following section.

\subsubsection{Pedagogical Design Principles}

The eGroups approach follows a learner-centred approach (Berghoff et al., 2000). The self-experience in an authentic setting, like that of a joint project work, is fostered by the institutional frame of the learning environment. Here, learners can act freely in the 
institutionally "safe" setting of a school, which does not impose existential pressure upon them like it would in real life (Walker \& vom Brocke, 2009). Thanks to the lecturer, learners are enabled to both reflect upon their experience as well as their knowledge about the object and to adapt their own behaviour to the changing situations (Garrison et al., 2001). At the same time, learners are confronted with unprecedented and largely unpredicted context situations - just like in evolving cooperations - in which they have to jointly work on an academic project and to fulfil the project tasks together even though the cooperation in its set up may bring a certain risk of conflicts with itself (O'Dowd, 2006). During the whole lecture and project period, the focus lies on enabling the students to develop and act autonomously (Lewis \& Walker, 2003). The degree of student autonomy needs to be adapted to the specific proficiency and needs of the learners (Schwienhorst, 2003).

The self-experience in evolving cooperations is - in merit of the protected learning context of the VLC -concentrated on the learner and on enabling the learner to become more and more autonomous (cf. Garrison et al., 2001). This is linked to the principle of reciprocity. Reciprocity in a subject-oriented learning set up incorporates that learners themselves become experts of their own unique characteristics. This way, learners can actually become competent in helping others. Linguistically for instance, first language speakers of English would be able to help, for instance German learners of English while these may in turn help the English learners of German. The principle of reciprocity also enables the students to reciprocally help one another on a contentoriented basis in that they are able to bring in and develop further their unique expert knowledge. Since all learners become dependent upon one another, the projects can only be carried out under the cooperative behaviour of everyone involved in the respective project team (cf. Stickler \& Lewis, 2008). Helping out others, last but not least, also increases students' awareness to the needs and requirements of others, which is an important step in becoming an agile communicator.

\subsubsection{Organisational Design Principles}

The organisational design principle delivers a frame for the pedagogical conception. Decisions taken here have an immediate effect on both intensity and quality of the project work in virtual learning and teaching scenarios (White, 2003). For the eGroups approach, certain design parameters can be deducted as part of the organisational design principle. They may help to take important decisions as well as to show options for adaptation to individual learner group requirements. The organisationally relevant decisions influence in how far learners can actively take part in the lessons and they have a strong motivational impact on the group. The expectations of learners then again influence in how far and how intensely they will shape the lessons. Examples for such parameters regard incentive setting, curricular integration, dynamisation and the gradual step-by-step introduction into the virtual learning environment (Salmon, 2002):

VLCs require a high level of motivation and willingness of students. As pointed out in Garrison et al. (2001), there is a complex interplay between social, cognitive and teaching presence in what they call "communities of inquiry" calling for dedicated and flexible communication skills from the students. From a content perspective, the choice of tasks and the communicative usage of the virtual learning environment may be positively enhance motivation and willingness by incentive setting (vom Brocke et al., 2010). Incentives may be valuable exchange of experiences, demanding tasks from a 
content-perspective, awards, future-oriented impact, etc. What seems particularly important in this respect is aligning the requirements of the course work with the curricula of the students so as to enable a subject-based exchange and to strive for content-oriented exchange.

In eGroups, learners have to organise themselves virtually in a newly set up team whose team members they do not know and by making use of various technical tools which may not be common to them at the beginning of their project work (Chun \& Plass, 2000). The lecturer, therefore, has the important role of dynamising all the VLCs and to motivate learners to make it a habit to regularly use the technical environment (Walker \& vom Brocke, 2009). The complexity of using all the technical tools adequately on a virtual platform as well as to orientate oneself may certainly become an obstacle for many. A strategy of introducing the technical surrounding carefully appears to be a promising strategy to overcome preconceptions and blockades. Salmon (2002) suggests a step-by-step introduction of virtual working strategies, which may have a positive effect on the learner's acceptance.

The basis for this is formed by a solid and clearly arranged technical design. It is characteristic to follow a purpose-oriented use of technical tools on a platform that is aligned with organisational and pedagogical principles of design.

\subsubsection{Technical Design Principles}

The technical design forms an important basis of a VLC concept. As to the huge variety of technical tools ready at hand, the challenge lies in identifying adequate systems for the specific purposes and to customise them appropriately (Walker \& vom Brocke, 2009). For both steps, the individual requirements of the specific course need to be identified which must be deducted from the pedagogical and the organisational design principles. What is important for the technical customisation from the pedagogical perspective is, therefore, learning goals, learning contents and methods as well as from an organisational perspective the introductory implementation steps and relevant parameters. Such a purpose-oriented use of technology shows how all design principles in the eGroups approach can be aligned.

A VLC, as it is aimed at in eGroups, stands in a certain relation to social networks which have taken over large parts of private life nowadays (Gartner, 2008). This allows for a more and more both competent and self-assured use of virtual tools. Yet, it cannot be built upon automatically for every student. Students may have an individual or even culturally different way of using virtual tools (Thorne, 2006) as may media competence be developed with varying degrees of competency from student to student (Chun \& Plass, 2008). Moreover, online communication itself is subject to dynamic change as users may vary there use or conception of the virtual platform (White, 2003: 91).

In order to visualise how the eGroups approach may be implemented in more detail and in order to show whether it actually reaches what it promises, the following chapter presents both the practical implementation and results of a languages for specific purposes course at the university of Münster in Germany. 


\subsection{Evaluating the eGroups-Model}

The eGroups approach has been implemented for over a period of four semesters in which it has been continuously shaped and further developed. In the following we present data from the fourth application case carried out as part of a joint cooperation between the University of Münster in Germany and the Massey University in New Zealand. The cooperation was placed into two courses: "English for Social Sciences and the Humanities", a course at the University of Münster in Germany including 15 students and the course "German for Advanced Learners" with five students at the School of Languages at Massey University Palmerston North. A combination of the students resulted into five teams altogether. Linguistically the collaboration was planned to be carried out 50\% in German and 50\% in English so that every party involved had the chance to gain linguistic insights. The actual contact time for students was set for a period of six weeks.

As to the second research question $\mathrm{R} 2$, following our research design, the application serves to evaluate the usefulness of the eGroups model according to the learning objectives (Hevner et al., 2004). In our study the particular purpose was to (1) evaluate as to in how far it is actually feasible to integrate such an approach into practice on a normal and regular basis; (2) evaluate in how far acting in evolving cooperations can actually be induced; (3) whether or not participants would actually develop their agilities in the course of their cooperation. The results will be presented in the following.

\subsubsection{Integration of the eGroups Approach}

The eGroups approach has been successfully implemented in two courses at both the Language Center of the University on Münster in Germany and the School of Languages at Massey University in New Zealand for a period of two years. Experience proves that the approach can be successfully managed on a regular basis. The courses have been monitored, evaluated and continuously improved. The following shows results from the eGroups implementation in 2008 as part of the courses "English for Social Sciences and the Humanities" and "German for Advanced Learners". The two courses have been interlinked and successfully completed an eGroups implementation in the first semester in 2008 .

\subsubsection{Evolving Cooperations in eGroups}

In order to be able to analyse in how far evolving cooperations do take place, the composition of the individual eGroups need to be described as to their characteristics. The following illustration shows the composition for an exemplary project group:

The students of the University of Münster took part in the course "English for Social Sciences and the Humanities" offered by the Language Centre as part of an on-site course with a Blended Learning part. The partner group at Massey University in New Zealand worked in a course designed for extra-mural students of the Humanities who frequented the course "German for Advanced Learners". Therefore, the aspect of diversity was fulfilled. The common goal was determined by the project goals as part of which the students had to work on a project about a specific topic together. 


\begin{tabular}{|l|l|}
\hline \multicolumn{2}{|c|}{ Constitutional Characteristics } \\
\hline $\begin{array}{l}\text { Diversity of stakeholders" } \\
\text { contexts }\end{array}$ & $\begin{array}{l}\text { Both on-site students with face-to-face and } \\
\text { blended learning lectures as well as extra-mural } \\
\text { students }\end{array}$ \\
\hline Common Goals & $\begin{array}{l}\text { Joint Paper about the topic "Energy } \\
\text { Consumption in Germany and New } \\
\text { Zealand" which was part of the given } \\
\text { overarching theme "Globalisation and } \\
\text { Localisation - Opportunities and Challenges. }\end{array}$ \\
\hline Project-based Cooperation & Six weeks on stretch in 2008 \\
\hline
\end{tabular}

\begin{tabular}{|l|l|}
\hline \multicolumn{2}{|c|}{ Typical Characteristics } \\
\hline Interculturality & $\begin{array}{l}\text { Students from Germany and New Zealand with } \\
\text { differing international experience. }\end{array}$ \\
\hline Interdisciplinarity & $\begin{array}{l}\text { Students with an academic background in } \\
\text { Psychology, History and Law. }\end{array}$ \\
\hline Interlinguality & $\begin{array}{l}\text { German mothertongue speakers and learners of } \\
\text { English and English mothertongue speakers and } \\
\text { learners of German. }\end{array}$ \\
\hline
\end{tabular}

Figure 2. One Exemplary eGroup as Part of the Cooperation between the University of Münster and Massey University

The student's task was to find a topic within the overarching theme of "Globalisation and Localisation. Opportunities and Challenges - Germany and New Zealand compared", to carry out a small empirical study together and to write an article about the study together. The students used both platforms the two universities had to offer with specific tools assigned to the use of the platforms: The university of Münster offered the virtual learning platform HERBIE which comprised a personalised user profile and an email service, a discussion board, a Wiki tool for joint text constructions and documents ready for download serving the group work. Massey University offered a chat- and voice-room from WebCT which allowed for simultaneous communication and also offered log-files so as to ensure all the data constructed was retrievable for group members again. The following figure shows the resources available for the students. 


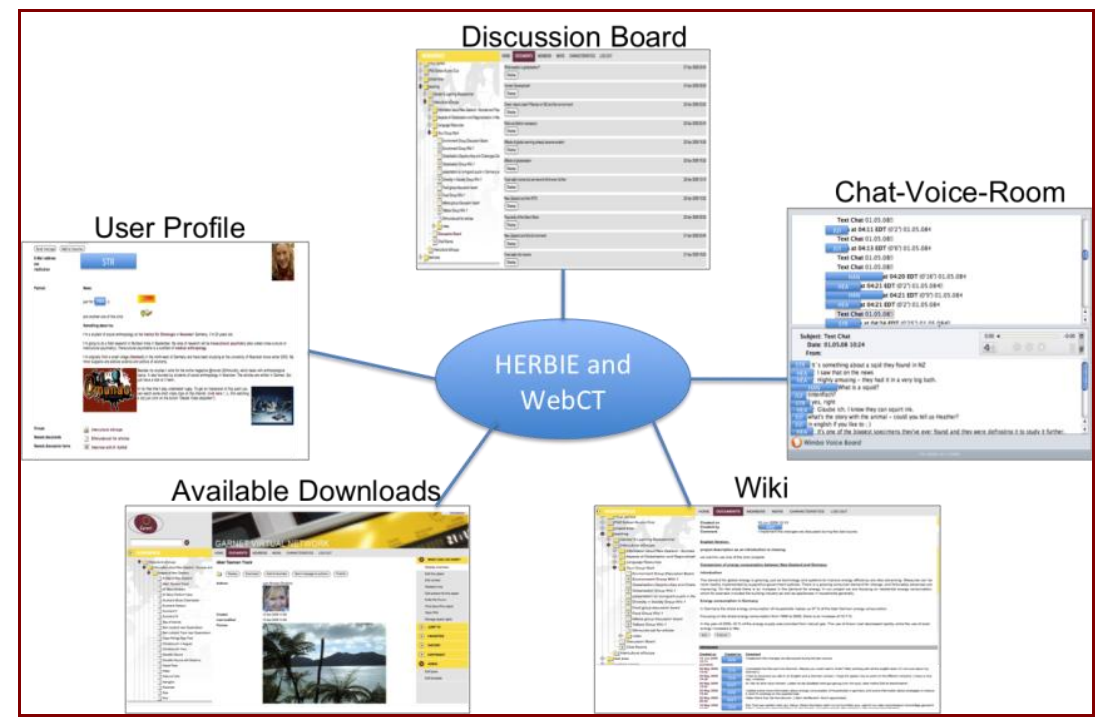

Figure 3. Virtual Learning Tools Available for eGroups Users

The exemplary eGroup we are focusing on in this paper, chose the topic "Energy Consumption in Germany and New Zealand" which corresponded to their personal or academic interest. The period of collaboration took place for six weeks contact time and was prepared by both groups beforehand. All students were students of the Humanities, yet, they all had their own specific subject background. Considering this, their different mother tongues and the different places where they lived, also the typical characteristics for evolving cooperations were all fulfilled.

\subsubsection{Learner Effects}

After having cleared whether eGroups was implementable at all and in how far the characteristics of evolving cooperations were fulfilled, it was now interesting to see in how far actually agile communication could be induced. The following shows excerpts of on eGroup which should help to evaluate. (A more detailed analysis can be found in vom Brocke, 2010).

The following example is a short excerpt from a first meeting in which the participants - one New Zealander and two Germans - meet up online for the first time in the voice - and chat room after having established contact already asynchronically in a forum and via email. The project phase the group is still in is characterised by organising the manner in which communication should occur and what the project should focus on. The citations in $>>\ldots<<$ indicate the translation by the author from German into English.

This example shows interintentional agility, which is the ability to formulate one's goal and to understand and consider the goals of the other cooperation partners adequately. KAT from New Zealand asks, what language should be chosen for the final paper knowing that a premise for the course was the use of 50\% German and 50\% English. Yet she also realises that the language for the term paper was not specifically set. She, therefore, aims at clarifying questions about the final joint product so as to not run the risk of having conflicting goals with the two Germans. As a learner of German, she probably prefers the use of German in as many parts as possible in the collaboration and 
the German students might just follow the opposite intention as they are learners of English.

KAT: “[...] Ja, auf welche(r) Sprache müssen wir dann ehm den Artikel schreiben?”

$>>K A T:$ “...] Well, on which language do we actually have to write the article?" $<<$

ANI: "Ich glaube, dass ehm unser Artikel auf Englisch sein muss, weil wir ja einen Englischkurs machen, aber ich hab nichts dagegen, dass wir den vielleicht auch auf Deutsch verfassen. ((1s)). Dann eben zwei Artikel."

>>ANI: "I think that our article needs to be written in English as we are doing an English course, but I wouldn't mind if we also wrote it in German. Then we'd just write two articles." $<<$

CIA: "Ja, das wäre eine Idee, also, dass wir den gleichen Inhalt sozusagen einmal auf Englisch und einmal auf Deutsch aufschreiben. So hat jeder davon etwas am Ende."

$>>C I A$ : "Yes, that would be a great idea, I mean, writing the same content both in English and in German. That way, we can all profit from the task." $<<$

\section{Figure 4. eGroup Coordination in the Team}

CIA from Germany takes up KAT's question and interprets her concern directly by saying that the German group needs to create the final paper in English. However, she adds that she would also be willing to create the same article also in German. By offering this, she anticipates a potential conflict and acts preventively by offering a solution KAT did not offer beforehand. The German student ANI goes along with CIA's proposal and verbalises the benefit for everyone involved: "This way, everyone of us can profit." CIA, therefore, acts in an interintentional agile way by considering all goals involved and by creating a solution that meets everyone's requirements.

Apart from examples about interintentional agility, the data in vom Brocke (2010) shows similar effects also for the other agilities. Thanks to the eGroups approach in the practical implementation it proves in fact feasible to induce evolving cooperations that require agile communication. A further question is now whether and in how far an agility development or change can be seen in the course of the participant's collaboration, which would mark a learning development.

\subsubsection{Agility Development}

In the course of the cooperation, every participant actually shows a change in his or her agility development (vom Brocke, 2010). In the group at focus for instance, the German participant "ANI" first acted according to her intentions without giving much empathy to the others' goals. KAT, the New Zealand student, actually communicated indirectly, thus, not clearly showing her intentions. These contrasting sorts of behaviour were bound to clash and it ultimately lead for both students to become more interintentionally agile. The following examples shall illustrate this change in behaviour:

The German student ANI quite directly overtook the role of the group manager. In that, she pushed and structured group activities and at the same time also communicated clearly the aspects she favoured. For instance she pushed forward the organisational 
process in getting the project running right away at the beginning: ANI (Chat-room, 01.05.08, Event 20): "First we should decide when we want to meet." She also structured when to use which language: ANI (Chat-room, 01.05.08, Event 80) “(...) we should also discuss eh when we speak German and when we speak English." And she organised when to meet: ANI (Chat-room, 01.05.08, Event 37) "Could we meet at 9.00am German time?". It was also her who first uttered the wish to narrow down the topic for the joint paper with respect to the course requirements: ANI (Chat-room, 01.05.08, Event 210): “(...) We should choose a topic we want to work on, eh it should involve both New Zealand and Germany and we should choose a research strategy we want to apply. So there may be a questionnaire or an interview." For the organisational process in the group, ANI's behaviour was surely adding speed and structure to the working progress of the cooperation. Yet, the way in which she communicates can be perceived as fairly direct, not leaving much space for joint brainstorming activities or creativity together. For instance, she does not formulate questions in order to involve others but she says what needs to be done in assertives like "we should...". When she does ask questions she inserts her personal wish right away. This style of communication can be perceived as quite straight forward.

In comparison, her New Zealand counterpart KAT seemed to communicate in an opposite manner trying to grasp the other students' opinions or academic foci. This can be interpreted as interdisciplinarily agile: KAT (Chat-room, 01.05.08, Event 106) "Do you guys have a specific interest in like a specific area of the environment that we'd like to do the project on?" and later: KAT (Chat-room, 01.05.08, Event 149) "Do you think we should focus on like one or two specific areas like for example how people might ehm look after the environment in their own ehm home or like in their surroundings or whether it (...) just covers the whole environment throughout New Zealand (...)“. KAT's style of communication involves her colleagues and seems far less direct in comparison to ANI. Linguistically, this is expressed by questions, leaving room for the others to formulate ideas. Hedges such as "like" also express this or "Do you think we should". She even uses waffling effects like "ehm" stressing uncertainty as to her proposals as well as modal verbs expressed in the conditional such as "should" or "might". KAT's style of communication can, consequently, be described as more indirect and rather modest in comparison to her German counterpart's style.

This combination of opposite communication styles lead to a clash calling for a change in agility of the both counterparts later on in the cooperation. The German student ANI suggested to carry out a questionnaire data collection in both countries. From her study background, she had a personal interest in questionnaire data collections. That way she both felt interested in carrying out such a data collection and she probably also felt her capabilities would suit the group. Since one work requirement for the group was to collect data that would allow for comparing or contrasting both countries, Germany and New Zealand, she urged KAT to distribute the questionnaires in New Zealand. The course requirements in New Zealand, however, were slightly different, so the New Zealand students did actually not have to get involved in a data collection. KAT preferred to evade an overload of work, yet she did not want to explicitly have to say she would not assist in the distribution of the questionnaires in question. Her German counterparts, however, did not understand this position since they did not interpret KAT's standpoint correctly. This lead to a phase of frustrations and KAT had to learn how to communicate her intentions by ultimately becoming more direct.

This development can be shown in the following example. The example has been shortened for reasons of legibility (vom Brocke, 2010, p. 218; p. 228f.). 


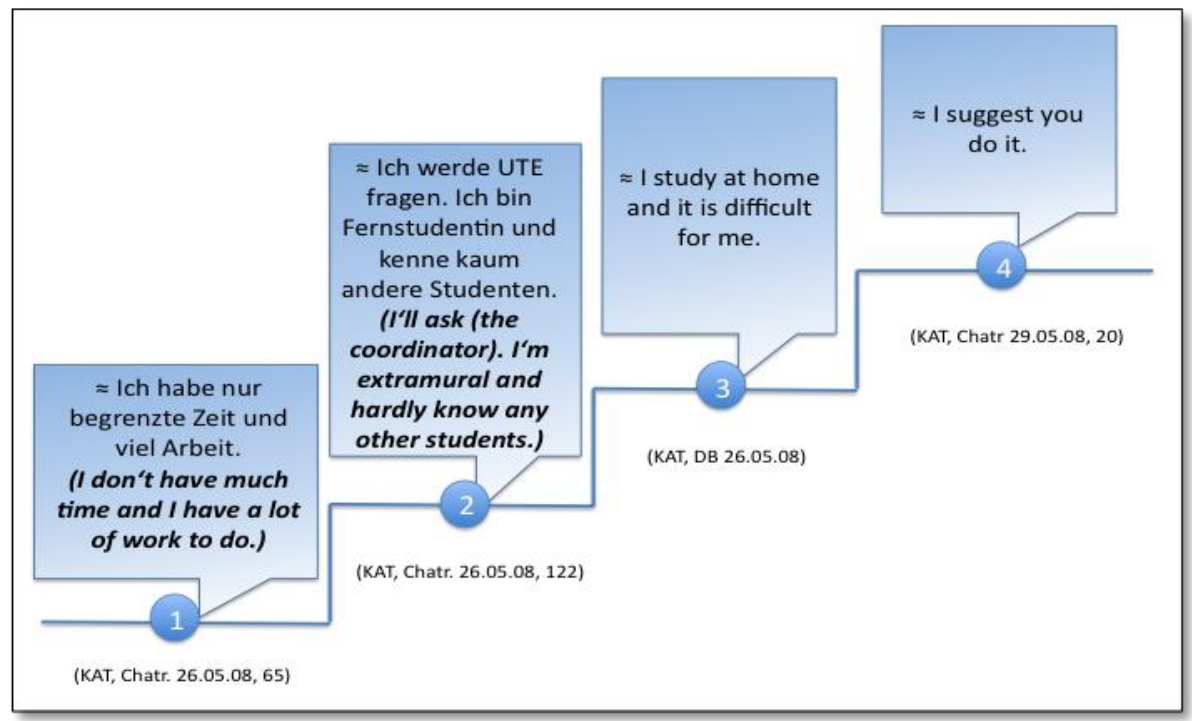

\section{Figure 5. Example of an Escalation: Increasingly Direct Communication (shortened) ${ }^{1}$}

The example shows the escalation in the collaboration of the eGroup which arose by New Zealander KAT's very careful and indirect style of communication in the beginning and her German counterparts not getting her intention through the subtleness of her wording. KAT first gave evading reasons stressing her context such as she only had little time and did hardly know any other students. She probably expected her counterparts to get the point and automatically help find a different proceeding. Since they did not react appropriately for her in that they kept asking her to distribute questionnaires in New Zealand, she was forced to become more direct. For doing so, she first changes the medium of communication by using the discussion board whereas the group had used the chat-room before and she switches from her foreign language German to her first language English. In the end she expresses "I suggest you do it." Interintentional agility means to align one's own goal with the goals of the other team members. This does not mean to give up one's own goals however. It seems obvious here that KAT has undergone a development of her communicative agilities. For the first time, she is forced to step up to her intentions more directly in order to evade doing something she is not happy with. At the same time she offers reparations in proposing to ask for help from somewhere else by involving the coordinator.

Similar examples are manifold in the data so that on the whole we can conclude that the participants have developed their agilities, which can be seen as a success in the eGroups approach. Doubtlessly future studies will be necessary to further ground these first results which have been documented at length in vom Brocke (2010). The following presents a short summary and an outlook on future research.

\footnotetext{
${ }^{1}$ The annotations in brackets refer to the location of the data in the data collection published in vom Brocke (2010). The abbreviation Chatr. refers to the Chat-/Voice-Room and DB refers to the Discussion Board.
} 


\section{Summary and Outlook}

In this paper we reported on research that shows how Virtual Learning Communities can actually be leveraged to substantially enable new learning scenarios. We conducted our study in the field of applied language teaching, where the development of "agile communication skills" is posing new challenges for educational institutions. In order to answer our first research question, we show how Virtual Learning Communities can be used to create an authentic learning environment of "evolving cooperation" - the socalled eGroups approach - in which students actually do experience "agile communication". While IT is key affording to interlink students from different universities worldwide, our research also shows that IT as such is not enough. It is rather needed to frame the IT use by carefully designed didactical and organisational settings. We build our findings on a longitude study of design-oriented research including formative evaluation in case studies over the past two years. In addition, we report on an in-depth case study applying the eGroups approach in a joint course at the Massey University New Zealand and the University of Münster. Our data collected in this study supports both the applicability and the usefulness of the approach, which answers our second research question.

The results of our study have to be viewed in the light of some limitations. First and foremost, our findings are limited to the field of application and the cases we studied. In the group studied it became clearly visible that each participant has undergone a development in their agility. This development was linked to the dynamics in the team and the increased attention paid to the needs of the project partners. In how far these results can be generalized, however, cannot be said so far. An interesting aspect to investigate would be what effect the initial agilities and the specific constellation of the group members have. One question also remains as to in how far there are actually interdependencies between agilities. Moreover, it could be interesting to find out what fully and successfully developed agility is actually able to effect and specifically, which agility would be useful for which specific use case.

Future research should focus on investigating further fields of application. If the approach for instance would be applied in a monolingual field, in which only English was the Lingua France, there would be less problems misunderstandings connected to the goal of applying the language. This would make sense for a course that specifies on a contentoriented focus in which the solution to a content-oriented problem lies at the centre of the cooperation. If all participants involved have to follow the same goals and fulfil exactly the same tasks, also problems in goal and workload defining might wane. A lot of different scenarios seem feasible for further eGroups implementations. One objective is to collect experience and integrate it in a reference model, which then will make it easier for teachers and lecturers to integrate eGroups in their courses more easily.

\section{References}

1. Anderson, T. (2000). E-moderating: The Key to Teaching and Learning Online: A Review. Journal of Distance Education/ Revue de l'éducation à distance, 15(1), 99-101.

2. Anderson, T., \& Garrison, D.R. (1998). Learning in a Networked World: New Roles and Responsibilities. In C. C. Gibson (Ed.), Distance Learners in Higher Education. Madison: Atwood, 97-112. 
3. Baumann, U., \& Shelley, M. (2006). Distance Learners of German and Intercultural Competence. Open Learning 21(3), 191-204.

4. Beerkens, R. (2010). Receptive Multilingualism as a Language Mode in the DutchGerman Border Area. Münster: Waxmann.

5. Belz, J.A. (2003). Telecollaboration. Language Learning and Technology, 7(2), 25.

6. Berghoff, B., Egawa, K.A., Harste, J.C., \& Hoonan, B.T. (2000). Beyond Reading and Wri-ting: Inquiry, Curriculum, and Multiple Ways of Knowing. Urbana, IL: National Council of Teachers of English.

7. Blum-Kulka, S., House, J., \& Kasper, G. (Eds.). (1989). Cross-cultural Pragmatics. Requests and Apologies. Norwood, N.J.: Ablex.

8. Boehm, B., \& Turner, R. (2004). Balancing Agility and Discipline: A Guide for the Perplexed. Boston: Addison-Wesley.

9. Buhlmann, R., \& Fearns, A. (2001). Handbuch des Fachsprachenunterrichts. Tübingen: Narr.

10. Bührig, K., \& Meyer, B. (2004). Ad-Hoc Interpreting and the Achievement of Communicati-ve Purposes in Doctor-Patient-Communication. In House, J. \& Rehbein, J. (eds.), Multilingual Communication. Amsterdam: John Benjamins, 4362.

11. Chun, D., \& Plass, J. (2000). Networked Multimedia Environments for Second Language Acquisition. In M. Warschauer; R. Kern (Eds.), Networked-Based Language Teaching: Concepts and Practice. Cambridge: Cambridge University Press, 151-170.

12. Cockburn, A. (2001). Agile Software-Development: Software Through People. Amsterdam: Addison-Wesley Longman.

13. Davies, S. (2003). Content-based Instruction in EFL Contexts. The Internet TESL Journal, IX(2).

14. Dudley-Evans, T., \& St. John, M.J. (1998). Developments in ESP: A Multidisciplinary Approach. Cambridge: CUP.

15. European Commission Enterprise and Industry. (2009). e-Skills for the 21st Century Fostering Competitiveness, Growth and Jobs. Retrieved on December 4, 2011 from http://ec.europa.eu/enterprise/sectors/ict/e-skills/support/.

16. Garrison D.R., Anderson, T., \& Archer, W. (2001). Critical Thinking, Cognitive Presence, Computer Conferencing in Distance Education. Computer Conferencing in Distance Education. American Journal of Distance Education, 15(1), 7-12.

17. Gartner Group. (2008). Gartner Highlights 27 Technologies in the Hype Cycle for Emerging Technologies. Gartner News. Retrieved December 4, 2011 from http://www.gartner.com/it/page.jsp?id=739613.

18. Gibson, R. (2002). Intercultural Business Communication. Oxford: OUP.

19. Gudykunst, W.B. (2003). Crosscultural and Intercultural Communication. Thousand Oaks: Sage.

20. Hauk, M., \& Youngs, B.L. (2008). Telecollaboration in Multimodal Environments: The Impact on Task Design and Learner Interaction. Computer Assisted Language Learning, 21(2), 87-124.

21. Hazzan, O., \& Dubinsky, Y. (2009). Agile Software Engineering. Berlin. Heidelberg: Springer. 
22. Herrell, E., Whiteley, R., \& Crumb, A. (2010). Enterprise Communications: The Next Decade. Ten Trends That Will Shape Unified Communications and Collaboration. Cambridge, MA: Forrester Research White Paper, 1-11.

23. Hevner, A.R., March, S.T., Park, J., \& Ram, S., (2004). Design Science in Information Systems Research. MIS Quartely, 28(1), 75-105.

24. Hofstede, G. (1980). Culture's Consequences: International Differences in Work- related Values. Thousand Oaks: Sage Publications.

25. Holmes, J., \& Stubbe, M. (2004). Strategic Code-Switching in New Zealand Workplaces: Scaffolding, Solidarity and Identity Construction. In House, J. \& Rehbein, J. (Eds.), Multilingual Communication. Amsterdam: John Benjamins, 133-154.

26. Hossain, L., \& Wigand, R. (2004). ICT Enabled Virtual Collaboration Through Trust. JCMC, 10(1).

27. House, J., \& Rehbein, J. (2004). Multilingual Communication. Amsterdam: John Benjamins.

28. Hudson, J.M., \& Bruckmann, A. (2000). IRS Français: The Creation of an Internetbased SLA Community. Computer Assisted Language Learning, 15(2), 109-134.

29. Hutchinson, T., \& Waters, A. (2006). English for Specific Purposes: a LearnerCentred Approach. Cambridge: CUP.

30. Mangenot, F., \& Nissen, E. (2006). Collective Activity and Tutor Involvement in E-Learning Environments for Language Teachers and Learners. Computer Assisted Language Instruction Consortium Journal, 23(3), 601-621.

31. O'Dowd, R. (2006). Telecollaboration and the Development of Intercultural Communicative Competence, Münchner Arbeiten zur Fremdsprachen-Forschung, Vol. 13. Berlin, Munich: Langenscheidt.

32. Rilling, S., \& Dantas-Whitney, M. (2009). Introduction: Authentivity, Creativity, and Locali-zation in Language Learning. In S. Rilling \& M. Dantas-Whitney (Ed.), Authenticity in the Language Classroom and Beyond: Adult Learners. Alexandria: TESOL.

33. Salembier, P., \& Benchekroun, T.H. (2002) Cooperation and Complexity in Sociotechnical Systems. Revue des sciences et technologies de l'information, Revue d'intelligence artificielle (RSTI RAI), 16(4-5).

34. Salmon, G. (2002). E-tivities: The Key to Active Only Learning. Sterling: Stylus Publishing Inc.

35. Schwienhorst, K. (2003). Learner Autonomy and Tandem Learning: Putting Principles into Practice in Synchronous and Asynchronous Telecommunications Environment. Computer Assisted Language Learning, 16(5), 427-443.

36. Scollon, R., \& Scollon, S. W. (2001). Intercultural Communication. A Discourse Approach. Oxford: Blackwell.

37. Seidlhofer, B. (2001). Closing a Conceptual Gap: The Case for a Description of English as a Lingua Franca. International Journal of Applied Linguistics, 2(11), 133-158.

38. Stickler, U., \& Lewis, T. (2008). Collaborative Language Learning Strategies in an Email Tandem Exchange. In S. Hurd; T. Lewis (Eds.), Language Learning Strategies in Independent Settings. Clevedon: Multilingual Matters, 219-237.

39. Thorne, S.L. (2006). Pedagogical and Praxiological Lessons from InternetMediated Inter-cultural Foreign Language Education Research. In J. A. Belz \& S. 
L. Thorne (Eds.), Internet-Mediated Intercultural Foreign Language Education. Boston, MA: Heinle \& Heinle, 2-30.

40. Trompenaars, F., \& Hampden-Turner, C. (1997). Riding The Waves of Culture: Understanding Diversity in Global Business. Maidenhead: McGraw- Hill.

41. vom Brocke, C. (2010). eGroups - eine Konzeption zur Vermittlung fachsprachlicher Hand-lungskompetenz in evolvierenden Kooperationen. Retrieved December 4, 2011, from: http://miami.unimuenster.de/servlets/DocumentServlet?id=5313.

42. vom Brocke, J., White, C., Walker, U., \& vom Brocke, C. (2010) Making UserGenerated Content Communities Work in Higher Education. On the Importance of Incentive Setting. In U.D. Ehlers \& D. Schneckenberg (Eds.), Changing Cultures in Higher Education. Berlin: Springer, 149-166.

43. Wainfan, L., \& Davis, P.K. (2004). Challenges in Virtual Collaboration: Videoconferencing, Audioconferencing, and Computer-Mediated Communications. Santa Monica: Rand.

44. Walker, U., \& vom Brocke, C. (2009). Integrating Content-Based Language Learning and Intercultural Learning Online: An International eGroups Collaboration. In A. Brown (Ed.), Proceedings of CLESOL 2008.

45. Warschauer, M., \& Meskill, C. (2002). Technology and Second Language Learning. In J. Rosenthal (Ed.) Handbook of Undergraduate Second Language Education. Mahwah, NJ: Lawrence Erlbaum, 303-318.

46. White, C. (2003). Language Learning in Distance Education. Cambridge: Cambridge University Press. 